\section{EFFECT OF HEAT LOAD TO THE FORMING MACHINES}

University of West Bohemia, Faculty of Mechanical Engineering

Department of Machine Design Pilsen, Czech Republic

e-mail: zdchval@kks.zcu.cz

When designing a forming machine for hot forming, it is necessary to take into account the effects of heat on the construction. Therefore, it is important to perform an in-depth analysis of the possible influences of temperature on individual parts of the machine and subsequent effects on durability of the construction and machine accuracy. The article deals with the thermal analysis of a crank forging press.

\section{Keywords:}

forming machines, hydraulic forging press, mechanical crank forging press, heat load, FEM simulation

\section{Introduction}

Currently, great emphasis is placed on product quality, which results in increased demands on the design of the forming machine. One of the most important factors affecting the accuracy of a forming machine is thermal effect on the structure. Especially during technological operations where the semifinished product has a high temperature, up to $1200^{\circ} \mathrm{C}$.

Each type of forming machine is specific, and therefore thermal analysis must be carried out separately for each forming machine.

The acquired knowledge should be taken into account when designing new forming machines.

\section{CKV 84/105 MN Hydraulic press}

The first representative to be analyzed was hydraulic forging press CKV 84/104 MN, Fig. 1, in 2011 [Chval 2009, 2011; Cechura 2010a, 2013]. The aim of the project was to verify thermal influence of the working area of this machine during the technological process of hot forming, Fig. 2, by thermal imager, Fig. 3, to identify critical areas to determine the extent and severity of this interaction and to provide recommendations for further progress in the issue of thermal effects.

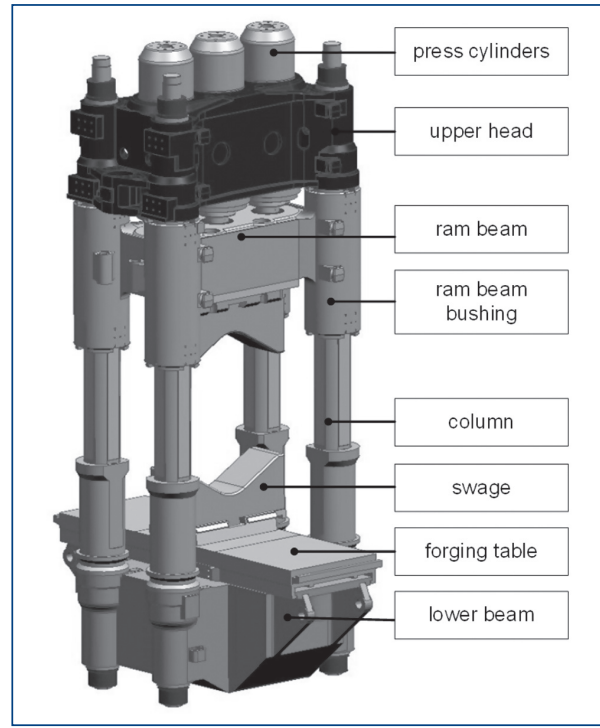

Figure 1. Hydraulic forging press CKV 84/104.

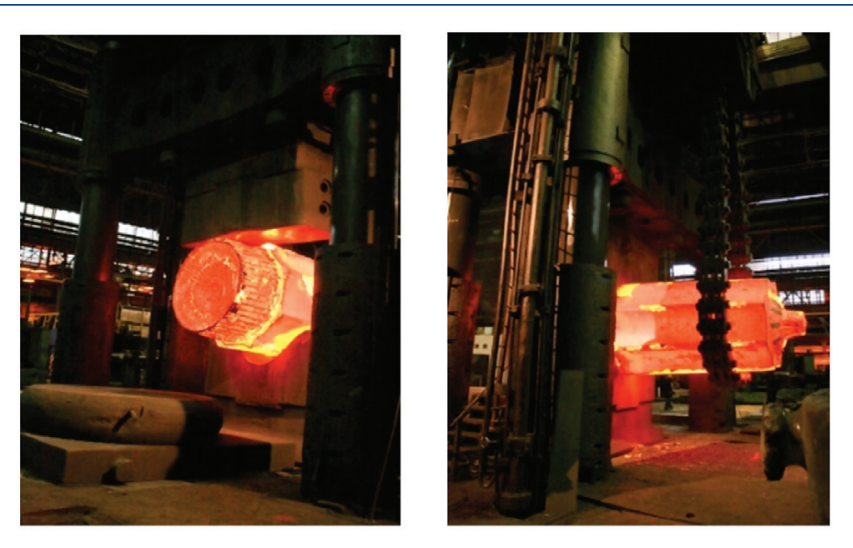

Figure 2. Hydraulic forging press CKV 84/104 during the forming process.

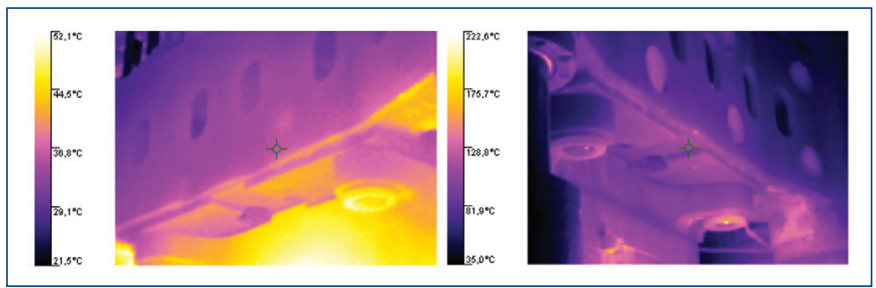

Figure 3. Surface temperatures on ram beam of hydraulic press CKV 84/104, thermal image.

Temperature measurement and next FEM calculation of the hydraulic press CKV 84/105 MN indicated that in this particular case the thermal effect is not relevant. Boundary conditions of FEM calculations based on experimental measurements. During the calculated period of time there were no significant temperature changes in the construction. The reason was the sufficient time for cooling of the press during technology breaks. Furthermore, the large size of the working space of the press, which does not enable absorption of large amounts of radiated heat into the construction.

From the forging operations through to ensuring the negligibility of thermal effects in a particular hydraulic press, there is a need for thermal analysis on the forging presses. The reason is the experience from practice of the complicated setup of ram clearance due to thermal effects.

After a two-year interval a mechanical crank forging press with a nominal force of $25 \mathrm{MN}$ was chosen for thermal analysis.

\section{Mechanical crank forging press $25 \mathbf{M N}$}

A mechanical crank forging press was chosen because it is assumed that it will have the largest thermal effects on the construction, especially the ram guidance, of all the analysed forging presses. This assumption is based on the knowledge of technological process practiced on mechanical forging presses. It is a solid welded stand, pre-tensioned by anchors.

Usually workforce is transmitted between the crankshaft and ram by a connecting rod. The ram and the connection rod are connected by a pin or sliding joint [Smeral 2013, Cechura 2010c].

In our particular case, the connecting rod is replaced by a bearing ring provided with a sliding surface which directly abuts the top surface of the ram [Cechura 2013]. It is therefore a press yoke system transmission of force, Fig. 4.

\subsection{Boundary conditions of thermal analysis}

When the boundary conditions were determined efforts were made to capture the least favorable conditions of the real state. The correct determination of boundary conditions is a necessary prerequisite for obtaining relevant results. Boundary conditions must be specified for each machine separately with regard to the operating technologies. 


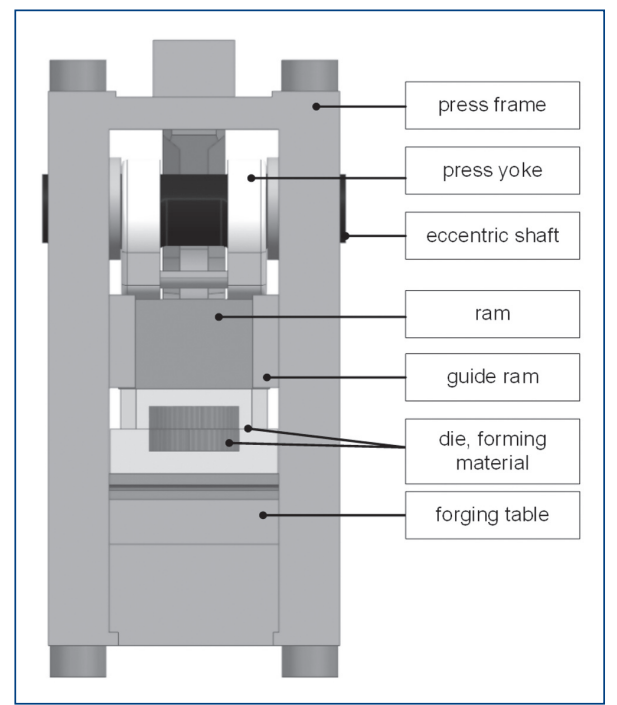

Figure 4. Mechanical crankshaft forging press $25 \mathrm{MN}$

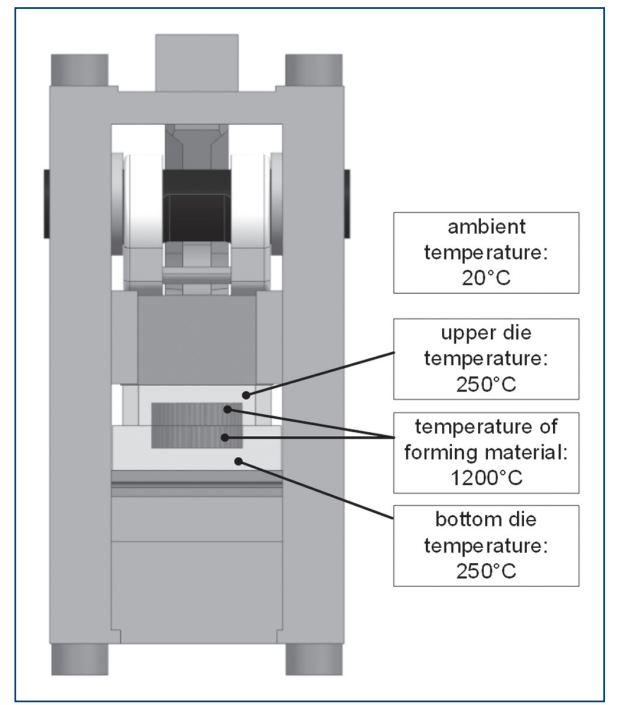

Figure 5. Boundary conditions of thermal calculation.

Press was loaded by, Fig. 5:

\section{Die temperatures}

Temperatures of both halves of the die were set to $250{ }^{\circ} \mathrm{C}$, which corresponds to normal preheating. This temperature is kept constant throughout the calculation time. The same is true during forging, which leads to continuous heating of dies at the desired temperature.

\section{Temperature of forged piece}

Forging temperature was set to $1200,800,400$ and $250{ }^{\circ} \mathrm{C}$ as a repeating cycle. Each temperature corresponds to one second in the time calculation. The temperature distribution simulates insertion of blank at a temperature of $1200{ }^{\circ} \mathrm{C}$ and forging it in one second. The remaining temperatures represent cooling the interior of the die until the insertion of a new blank.

\section{External conditions}

Ambient temperature of the press was set to $20^{\circ} \mathrm{C}$. The airflow around the press was selected as minimum $0.1 \mathrm{~mm} / \mathrm{s}$.

Each part of the press was connected by thermal contacts simulating heat conduction or radiation.

\subsection{The results of thermal analysis}

The results of the calculation represent the thermal state of the structure after five hours of operation, for the boundary conditions defined above.

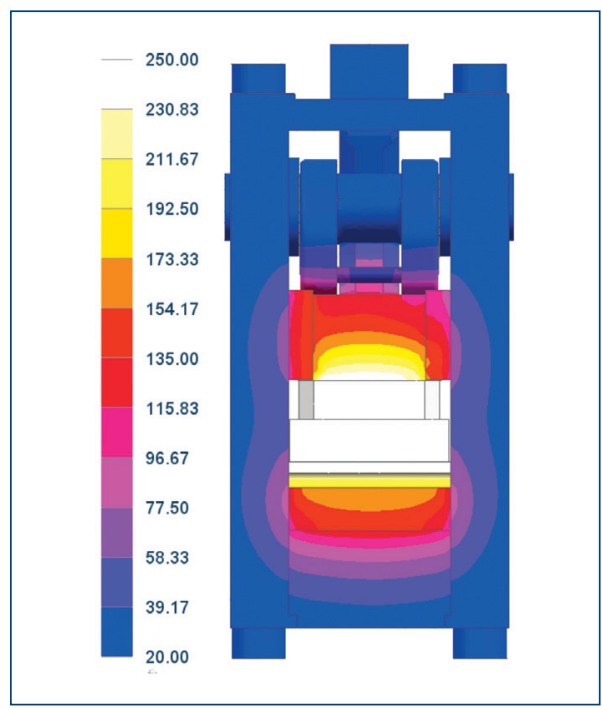

Figure 6. Results of thermal analysis of the machine after five hours $\left({ }^{\circ} \mathrm{C}\right)$

As can be seen in Fig. 4, the maximum temperature does not exceed the temperature of the preheated dies, $250{ }^{\circ} \mathrm{C}$. We can therefore conclude that the source of the heat load in this case is not the molded piece, but primarily the preheated die. The calculation shows that in this case the influence of heat load on the machine cannot be ignored. Especially, thermal influence of guide ram can't be ignored. The maximum temperature reached inside the ram guidance is $162{ }^{\circ} \mathrm{C}$ and the maximum temperature difference between the front and the back guidance is $16^{\circ} \mathrm{C}$, Fig. 5 . We can say that the temperature will have a significant impact on defining the clearance of the ram guidance. The temperatures are the maximum temperatures achieved by FEM calculation.

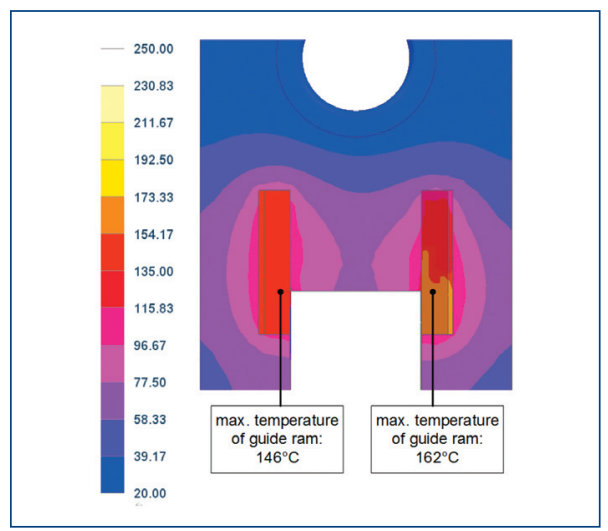

Figure 7. Results of thermal analysis of ram guidance after five hours $\left({ }^{\circ} \mathrm{C}\right)$.

Another necessary step was the structural calculation for obtaining the results of stress and displacement of parts of the structure from the effects of heat load.

\subsection{Boundary conditions for structural analysis}

Only thermal load resulting from thermal analysis was inserted into the structural calculation.

Anchoring of stand was at the bottom of the rack over a circular area defined by the axis of the rack.

All inserted parts of the press (eccentric shaft, ram, connecting rods, anchors) inserted using contacts. 
Clearance of the guidance was equally determined to $0.1 \mathrm{~mm}$, clearance in the bearings to $0.2 \mathrm{~mm}$.

\subsection{The results of structural analysis}

The results represent the state of the structure loaded by temperature after five hours of forging. The result of stress, Fig. 8 and 9 , shows that the heat loads cause significant structural loads. Fig. 8 and 9 show the stress distribution in the structure of the press. All gray fields representing stress above $180 \mathrm{MPa}$ represent dangerous places for dimensioning of machines.

The largest stress in the press, up to $390 \mathrm{MPa}$, is above the bearing housing - the mount of the eccentric shaft in the frame. Another risk area is at the bottom of the frame around the forging table. Increased stress is caused by thermal expansion of the forging table. It is important to emphasize that the chosen boundary conditions are very unfavorable, Fig. 5, and the values obtained, Fig. 8, 9, will probably not be achieved in the operation of the machine.

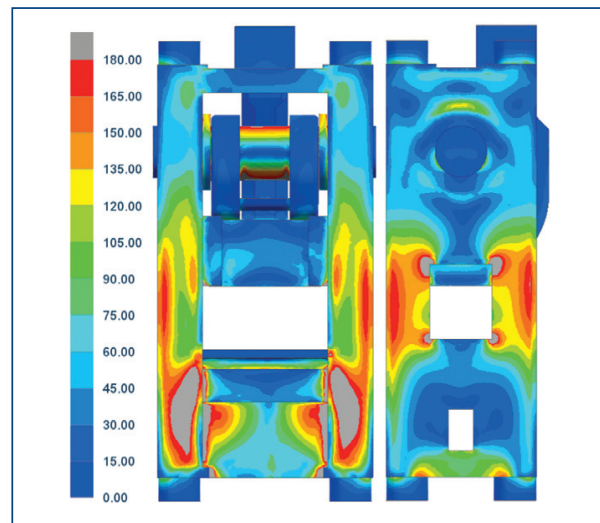

Figure 8. Stress $(\mathrm{MPa})$, view of the press.

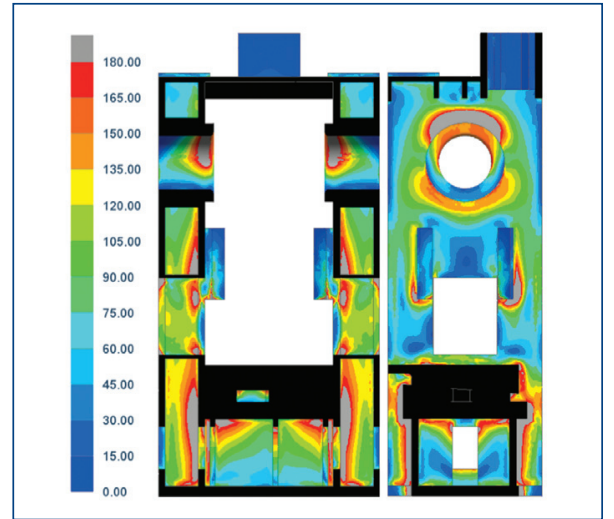

Figure 9. Stress $(\mathrm{MPa})$, section of press frame.

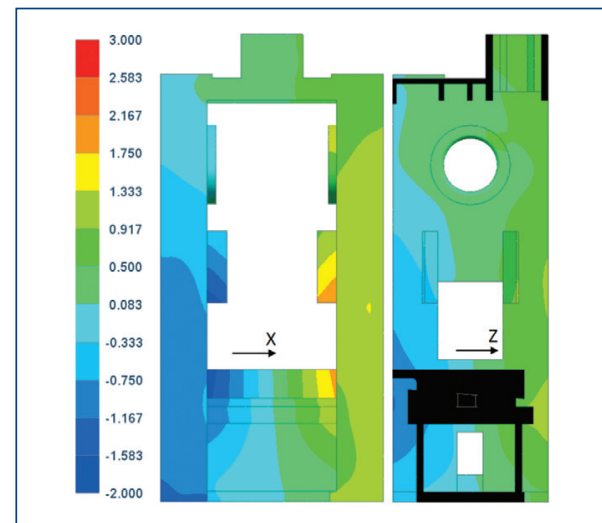

Figure 10. $X$ and $Z$ direction displacement $(\mathrm{mm})$.

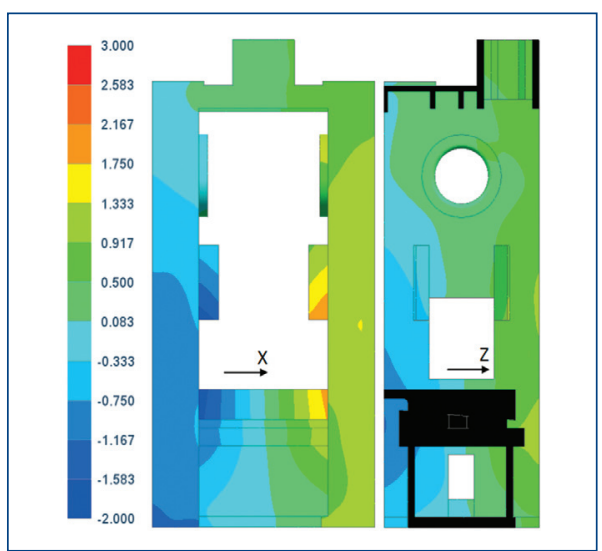

Figure 11. Y direction displacement $(\mathrm{mm})$.

Displacement in the $X$ and $Z$ direction, Fig. 10, shows that the displacement of ram guidance is in the order of tenths of a millimeter. In the case of displacement in the $X$ direction there is a difference of $1.2 \mathrm{~mm}$ and displacement in the $Z$ direction is 0.54 $\mathrm{mm}$. Displacement is measured as the difference in displacement at the top and bottom of the guide.

Displacement in the $Y$ direction, Fig. 11, between the press table and eccentric bearing shaft is $0.55 \mathrm{~mm}$. This displacement will affect setting of dies.

\section{Conclusion}

The aim of this article is to highlight the importance and seriousness of thermal loading on forming machines, and especially to notify producers of forming machines that thermal loading cannot be neglected in machine design but on the contrary it must be given due attention.

The analysis shows that the thermal load of the machine is important and will influence stress in the construction and this will significantly influence the clearance adjustment in the ram guidance.

It is important to emphasize that the chosen boundary conditions are very unfavorable and the values obtained will probably not be achieved in the operation of the machine. It is the assumption that during forging there will be technological breaks when the machine can cool down, and also the airflow in the forge will be greater than envisaged.

Solving effects of heat load to the forging presses is very challenging and it will be necessary to verify the results by experimental measurements. Future work should focus on refining the boundary conditions so as to allow us to say that the thermal load on a specific machine and technological conditions are relevant or not.

With regard to the energy balance of the whole technological process, we need to think about how to limit the amount of energy wastefully escaping into heating the components of the machine [Cechura 2011, 2010b].

\section{Acknowledgements}

The article was supported by the motivation system of the University of West Bohemia, part of the postdoctoral programme [zcu.cz 2013].

\section{References}

[Cechura 2010a] Cechura, M., at al. Functions and features monitoring of forming machines, Report V-10-091, VSCVTT, Technical University in Prague, 2010.

[Cechura 2010b] Cechura, M., at al. Energy analysis of forming machines and further proposals for decreasing of energy consumption, Report, V-10-090, VSCVTT, Technical University in Prague, 2010

[Cechura 2010c] Cechura, M., at al. J. Development Of New And Innovations Of Existing Construction Solutions Of Forming 
Machines, Report CK-SVT-WP11, CVTS, University of West Bohemia, Pilsen, 2010

[Cechura 2011] Cechura, M., at al. Energy Analysis of Forming Machines and Further Proposals for Decreasing of Energy Consumption, Report, V-11-037, VSCVTT, Technical University in Prague, 2011

[Cechura 2013] Cechura, M., Chval, Z. Convectional versus multiple operating press, Kovarenstvi, May 2013/17, 67-70, ISSN 1213-9289

[Chval 2009] Chval, Z., Stanek, J. Temperature effect of molded piece to forming machine, Bratislava, 2009 ISBN 978-80-227. 3135-5

[Chval 2011] Chval, Z. Reducing material costs and effect of heat load of forming machines, Ph.D. Dissertation, Faculty of Mechanical Engineering, Department of Machine Design, University of West Bohemia, Pilsen, Czech Republic, 2011.
[Kubec 2013] Kubec, V., Raz, K. Two-columns versus fourcolumns hydraulic press, Convectional versus multiple operating press, Kovarenstvi, May 2013/17, 67-70, ISSN 1213-9289

[Smeral 2013] http://www.smeral.cz, Smeral Brno, Accessed on: 2013-06-13

[zcu.cz 2013] http://www.zcu.cz/research/Grantovy-system/motivacnisystem/2013/cast_POSTDOC_2013, University of West Bohemia, Accessed on: $201 \overline{3}-06-13$

\section{Contacts}

Ing. Zdenek Chval, Ph.D.

University of West Bohemia

Faculty of Mechanical Engineering

Department of Machine Design

Univerzitni 8, 30614 Pilsen, Czech Republic

tel.: 739429 970, e-mail: zdchval@kks.zcu.cz 